\title{
Effectiveness of Integrated Model of Emotionally-Focused Therapy and Gottman's Model in Internal Cohesion and Reduction of Controlling Behaviors in Couples Faced with Marital Infidelity
}

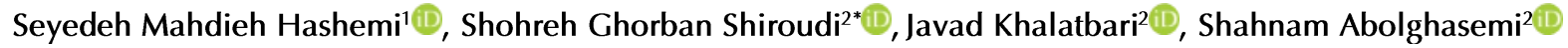 \\ 1 PhD Student, Department of Psychology, Tonekabon Branch, Islamic Azad University, Tonekabon, Iran \\ 2 Associate Professor, Department of Psychology, Tonekabon Branch, Islamic Azad University, Tonekabon, Iran
}

*Corresponding author:

Shohreh Ghorban Shiroudi,

Department of Psychology,

Tonekabon Branch, Islamic Azad

University, Tonekabon, Iran

Tel: +989125211654

Email: Drshohrehshiroudi@gmail.com

Received: 12 Jun. 2020

Accepted: 12 Jul. 2020

ePublished: 01 Nov. 2020

\begin{abstract}
Background and Objective: Marital infidelity is considered a shocking issue for couples and families and common phenomenon for counselors and therapists. The purpose of this study was to compare the effectiveness of an integrated model of emotionally-focused therapy (EFT) and Gottman's model in internal cohesion and reduction of controlling behaviors in couples faced with spousal betrayal.

Materials and Methods: This quasi-experimental study was carried out on two experimental groups and one control group with a pretest-posttest design. The statistical population of the study included all the women referring to one of the counseling centers in Tehran, Iran, during 2018-2019 due to marital conflicts, problems related to satisfaction, and need for the improvement of marital relationships. The study population was chosen based on purposive sampling after the random screening. The data were collected by the Internal Cohesion Questionnaire and Controlling Behaviors Questionnaire. Descriptive and inferential statistical methods and multivariate analysis of covariance were used to eliminate the effect of pretest using SPSS software (version 22).

Results: The obtained results showed that the integrated model of EFT and Gottman's model had a greater effect on the comprehensibility of the experimental groups than that of the control group. Moreover, the findings demonstrated that EFT and Gottman's model had a significant effect on the reduction of controlling behaviors $(\mathrm{P}<0.001)$. The results also revealed that the integrated model of EFT and Gottman's model had a significant effect on internal cohesion and controlling behaviors, and this effect was lasting at follow-up $(\mathrm{P}<0.001)$.

Conclusion: It can be concluded that the combination of EFT and Gottman's therapy is an effective pattern in couples affected by infidelity and can be used as one of the therapeutic or educational methods in couple therapy programs.
\end{abstract}

Keywords: Couple therapy, Emotions, Extramarital relations, Marriage, Spouses

\section{Background}

Marital infidelity is considered a shocking issue for couples and families and common phenomenon for counselors and therapists [1]. Extramarital affairs create a great deal of confusion for couples. Based on the evidence, it was shown that most individuals expect monogamy and no extramarital affairs from their spouses [2-5]. The main victims of this phenomenon in the family environment are first women and then children and finally men [6]. Controlling is a problem that has received more attention in recent centuries. The main premise of controlling is that if individuals feel dissatisfied with a relationship, they will not feel responsible for it; however, they blame others and those out of control $[7,8]$.
Internal cohesion is considered one of the factors which are effective in the reduction of harms and controlling behaviors among couples faced with marital infidelity [9, 10]. Antonovsky defined the concept of internal cohesion while focusing on the model, which supports factors leading to human health and well-being instead of the ones resulting in diseases [11, 12]. Although this concept has three dimensions, they are practically defined on a single scale theoretically reflecting the general direction of life [13]. Feelings of strong inner cohesion are related to a high capacity for mental and physical coping with stress and challenges occurring throughout an individual's life [14]. Therefore, studies demonstrated that individuals 
with strong cohesion are more successful in coping with stress [15].

One of the therapies increasing internal cohesion among couples faced with marital infidelity and improving the reduction of controlling behaviors is the integrated model of emotionally-focused therapy (EFT) and Gottman's model [16]. Accordingly, some efforts have been made to combine specific components of different approaches in a systematic manner and coherent and integrated model. Integrated approaches have unique benefits, including creating a broader basis for intervention and flexibility in the clients' therapy [17]. Today, Gottman and Johnson are known as effective scholars in couple therapy [18] by developing a variety of training programs to strengthen couples' relationships. Gottman's theory is an integrated approach that is based on the doctrinal principles of various systemic, existential, psychoanalytical, and behavioral theories [19]. Similarly, Johnson emphasizes relationships, attachment styles, and interaction cycles in EFT [20].

The EFT refers to the important role of emotions and communication in organizing communicational patterns and regards emotions as change factors [21]. The EFT aimed to help couples achieve latent emotions and facilitate positive interactions. In addition, in a study on EFT for couples whose spouses have breast cancer, with a theoretical basis and descriptive case study, Adamson [22] observed that for a couple with a sick spouse, both spouses experience a great deal of emotional distress. Furthermore, Soltani et al. [23] demonstrated that EFT reduces couples' distress.

Gottman's [24] therapeutic approach includes organized programs and methods called regular and logical treatment processes, designed to deepen friendships, strengthen dispute management, and create common sense and purposefulness in couples' relationships [25]. Furthermore, Davis D, Shaver PR, and Vernon [26] investigated the effectiveness of Gottman's approach in relationship satisfaction, quality of friendship, and destructive marital conflicts within a year. In addition, Rajaee [27] showed the effect of Gottman's intervention on the reduction of emotional divorce. Razi [28] indicated that teaching Gottman's conflict resolution skills increases marital satisfaction.

Since couples faced with marital infidelities face many psychological, social, and emotional problems and harms, leading to tensions in various dimensions, it is difficult to regulate their emotions, beliefs, thoughts, and interpersonal relationships.

\section{Objectives}

This study aimed to determine the effectiveness of the combined model of EFT and Gottman's model in internal cohesion and reduction of controlling behaviors in couples faced with marital infidelity.

\section{Materials and Methods}

This quasi-experimental study was carried out on two experimental groups and one control group with a pretest-posttest design. The statistical population of the study included all the women referring to one of the counseling centers in Tehran, Iran, (i.e., Ganj-e-Daroun Flourishing Counseling Center, Third Way Center, and welfare-related centers) during 2018-2019 due to marital conflicts, problems related to satisfaction, and need for the improvement of marital relationships. The study population was chosen based on purposive sampling after the random screening.

\section{Internal Cohesion Questionnaire}

It is a 50 -item questionnaire developed by Kimiai, Arqabai, and Jozi in 2013. This questionnaire has three subscales for the measurement of the levels of individual comprehensibility, manageability, and meaningfulness of events. The significant scales include 23 items, 6 manageability scales, and 20 comprehensibility scales, scored based on a 5point Likert scale from very low (1) to very high (5). The minimum and maximum scores are considered 5 and 115 , respectively. The higher and lower scores indicate higher and lower internal cohesion, respectively. The Internal Cohesion Questionnaire has a good internal consistency, and the Cronbach's alpha coefficients are $0.935,0.92$, 0.65 , and 0.886 for the whole scale, significant subscale, manageable subscale, and comprehensible subscale, respectively [29].

\section{Controlling Behaviors Questionnaire}

The marital controlling behaviors scale was developed in 2005 by Graham-Kavan and Archer for the evaluation of controlling behaviors. This is a 24-item tool examining the couples' controlling behaviors in marital life. Five more items were added to the scale for the couples who have children. The respondent should determine on a 5 -point Likert scale (from 0 to 4 ) to what extent the spouse and his wife perform each one's desired behaviors. The minimum and maximum scores are considered 0 and 96, respectively. The Cronbach's alpha coefficients are $0.95,0.82,0.71$, $0.88,0.69,0.84$, and 0.90 for the whole scale, children's phrase subscales, economic control subscale, threatening control subscale, controlling through intimidation subscale, emotional control subscale, and control through isolation subscale, respectively [30]. 
Table 1. Teaching the integrated Gottman's model and emotionally-focused therapy

\begin{tabular}{|c|c|}
\hline Session & Content \\
\hline First & $\begin{array}{l}\text { Establishing professional and empathetic communication; familiarizing with members and asking questions about their } \\
\text { expectations from attending the training course; stating the goals and rules of the training sessions; completing research } \\
\text { questionnaires as a pretest }\end{array}$ \\
\hline Second & $\begin{array}{l}\text { Familiarizing with the types of attachment styles; familiarizing with the cycle of negative interactions; identifying } \\
\text { underlying and unexpressed emotions }\end{array}$ \\
\hline Thir & Summarizing the concepts of emotionally-focused therapy \\
\hline Fourth & Familiarizing with a variety of daemon dialogue patterns \\
\hline Fifth & $\begin{array}{l}\text { Familiarizing with the concept of raw situations and the importance of identifying these situations; revisiting a rocky } \\
\text { moment }\end{array}$ \\
\hline Sixth & Familiarizing with divorce indicators and four riders of destiny; familiarizing with the style of starting arguments \\
\hline Seventh & $\begin{array}{l}\text { Familiarizing with the specifications of various types of marital infidelity and seven principles of a secure relationship } \\
\text { house introduced by Gottman (1999) }\end{array}$ \\
\hline $\begin{array}{l}\text { Eighth } \\
\text { and Ninth }\end{array}$ & $\begin{array}{l}\text { Accepting influence and compromise (i.e., fourth principle); teaching ways to manage solvable problems (i.e., fifth principle), } \\
\text { ways to overcome perpetual problems (i.e., sixth principle), and creating shared meaning (i.e., seventh principle) }\end{array}$ \\
\hline Tenth & $\begin{array}{l}\text { Facilitating the expression of needs and wishes as well as new solutions to old problems; healing injuries; consolidating } \\
\text { new situations and positive interactive cycle; closing sessions; performing posttest and survey on participants }\end{array}$ \\
\hline
\end{tabular}

The inclusion criteria were interest and commitment to active and regular attendance at therapy sessions, no history of severe mental and emotional disorders, and no addiction, conflicts, and problems related to marital infidelity. The experimental groups participated in 10 sessions of 90 and 120 min, and the techniques and methods of communication imaging and integrated model of EFT and Gottman's model were presented step by step through weekly assignments and regular exercises by a consultant.

To observe ethical and professional principles, the researcher obtained the voluntary consent of all the study subjects for participation in the study. The integrated Gottman's model and EFT was developed by the researcher under the supervision of professors using theoretical and research backgrounds, concepts of exciting approach, and intervention program developed by Johnson based on the EFT model and Bowlby Attachment Theory [30], and some key categories of the Gottman's model (Table 1).

The statistical methods, descriptive methods (e.g., mean and standard deviation), and Levene's test were used to analyze the data. Analysis of covariance was utilized to test the hypotheses by SPSS software (version 22).

\section{Results}

The descriptive findings included the statistical indicators (e.g., mean and standard deviation), number of sample subjects, and frequency table and percentage, which are presented for all the variables in the following tables (Tables 1-4).

Table 2. Mean and standard deviation of study variables based on assessment stage in study groups

\begin{tabular}{|c|c|c|c|c|c|}
\hline Group & Variable & Index & Pretest & Posttest & Follow-up \\
\hline \multirow{4}{*}{ Internal cohesion } & \multirow{2}{*}{ Control } & Mean & 13.10 & 80.10 & 20.98 \\
\hline & & SD & 40.90 & 65.60 & 62.60 \\
\hline & \multirow{2}{*}{ Experimental } & Mean & 67.11 & 93.15 & 93.14 \\
\hline & & SD & 14.01 & 43.11 & 11.02 \\
\hline \multirow{4}{*}{ Understandability } & \multirow{2}{*}{ Control } & Mean & 56.47 & 54.20 & 51.93 \\
\hline & & SD & 8.32 & 7.30 & 7.30 \\
\hline & \multirow{2}{*}{ Experimental } & Mean & 60.87 & 81.20 & 80.07 \\
\hline & & SD & 7.31 & 8.12 & 7.88 \\
\hline \multirow{4}{*}{ Manageability } & \multirow{2}{*}{ Control } & Mean & 10.47 & 12.00 & 10.00 \\
\hline & & SD & 2.47 & 2.36 & 2.36 \\
\hline & \multirow{2}{*}{ Experimental } & Mean & 12.53 & 17.0 & 16.20 \\
\hline & & SD & 3.11 & 4.18 & 4.18 \\
\hline \multirow{4}{*}{ Significance } & \multirow{2}{*}{ Control } & Mean & 39.20 & 38.60 & 36.27 \\
\hline & & SD & 6.06 & 4.42 & 3.51 \\
\hline & \multirow{2}{*}{ Experimental } & Mean & 41.27 & 54.33 & 53.67 \\
\hline & & SD & 8.43 & 7.90 & 7.86 \\
\hline \multirow{4}{*}{ Controlling behaviors } & \multirow{2}{*}{ Control } & Mean & 53.60 & 52.93 & 58.80 \\
\hline & & SD & 7.40 & 7.44 & 7.19 \\
\hline & \multirow{2}{*}{ Experimental } & Mean & 56.73 & 16.53 & 24.13 \\
\hline & & SD & 8.66 & 5.68 & 5.94 \\
\hline \multirow{4}{*}{ Economic control } & \multirow{2}{*}{ Control } & Mean & 8.87 & 9.00 & 10.13 \\
\hline & & SD & 2.50 & 2.48 & 2.47 \\
\hline & \multirow{2}{*}{ Experimental } & Mean & 8.67 & 3.20 & 4.27 \\
\hline & & SD & 1.35 & 1.70 & 1.75 \\
\hline
\end{tabular}




\begin{tabular}{|c|c|c|c|c|c|}
\hline \multirow{4}{*}{ Threatening control } & \multirow{2}{*}{ Control } & Mean & 9.00 & 8.73 & 9.47 \\
\hline & & SD & 2.24 & 2.34 & 1.92 \\
\hline & \multirow{2}{*}{ Experimental } & Mean & 9.87 & 2.40 & 3.67 \\
\hline & & SD & 2.39 & 1.40 & 1.68 \\
\hline \multirow{4}{*}{$\begin{array}{l}\text { Controlling through } \\
\text { intimidation }\end{array}$} & \multirow{2}{*}{ Control } & Mean & 7.20 & 7.27 & 8.47 \\
\hline & & SD & 1.57 & 1.87 & 1.81 \\
\hline & \multirow{2}{*}{ Experimental } & Mean & 8.33 & 2.87 & 4.20 \\
\hline & & SD & 2.44 & 1.30 & 1.15 \\
\hline \multirow{4}{*}{ Emotional control } & \multirow{2}{*}{ Control } & Mean & 9.35 & 9.27 & 10.27 \\
\hline & & SD & 2.45 & 2.52 & 2.52 \\
\hline & \multirow{2}{*}{ Experimental } & Mean & 10.33 & 3.07 & 4.47 \\
\hline & & $\mathrm{SD}$ & 2.69 & 1.10 & 0.83 \\
\hline \multirow{4}{*}{$\begin{array}{l}\text { Controlling through } \\
\text { isolation }\end{array}$} & \multirow{2}{*}{ Control } & Mean & 9.13 & 8.80 & 9.87 \\
\hline & & SD & 2.17 & 2.01 & 1.96 \\
\hline & \multirow{2}{*}{ Experimental } & Mean & 9.33 & 2.40 & 3.67 \\
\hline & & SD & 2.53 & 1.40 & 1.40 \\
\hline \multirow{4}{*}{ Children-related control } & \multirow{2}{*}{ Control } & Mean & 9.87 & 9.87 & 10.60 \\
\hline & & SD & 2.03 & 2.03 & 2.16 \\
\hline & \multirow{2}{*}{ Experimental } & Mean & 10.20 & 2.60 & 3.87 \\
\hline & & SD & 2.87 & 2.03 & 2.03 \\
\hline
\end{tabular}

SD: Standard deviation

Table 3. Multivariate analysis of covariance of internal cohesion and controlling behaviors scores in three groups

\begin{tabular}{lccccccc}
\hline Statistical index/Effect & Test & Value & F & Df hypothesis & Df error & Sig & Eta coefficient \\
\hline \multirow{2}{*}{ Difference among three } & Pillai's Trace & 1.06 & 14.25 & 6.00 & 76.00 & 0.001 & 0.53 \\
groups and pretest effect & Wilks' Lambda & 0.04 & 52.74 & 6.00 & 74.00 & 0.001 & 0.81 \\
control & Hotelling's Trace & 24.20 & 145.22 & 6.00 & 72.00 & 0.001 & 0.92 \\
& Roy's Largest Root & 24.10 & 305.20 & 3.00 & 38.00 & 0.001 & 0.96 \\
\hline
\end{tabular}

Table 4. Results of univariate analysis of covariance

\begin{tabular}{|c|c|c|c|c|c|c|c|}
\hline Statistical index/Variable & Source of change & SS & Df & MS & $\mathrm{F}$ & $\mathbf{P}$ & Eta Square \\
\hline \multirow{2}{*}{ Internal cohesion } & Group & 13893.73 & 2 & 6946.87 & 41.82 & 0.001 & 0.68 \\
\hline & Error & 6478.19 & 39 & 16.11 & & & \\
\hline \multirow{2}{*}{ Controlling behaviors } & Group & 11703.53 & 2 & 5851.77 & 56.21 & 0.001 & 0.79 \\
\hline & Error & 1083.89 & 39 & 27.79 & & & \\
\hline
\end{tabular}

The three groups were homogeneous based on the distribution of the demographic variables. Before performing the analysis of variance, the ShapiroWilk and Levene's tests were used to examine the required assumptions. The Shapiro-Wilk test for the distribution of the study variables in the pre- and posttest stages indicated that the study variables had a normal distribution. The Levene's test was used to predict the homogeneity of the error variances. The results of the Levene's test showed that the homogeneity assumption of variances was accepted. In addition, examining the homogeneity of regression slopes demonstrated that the assumption of homogeneity of regression slopes was established. Therefore, there were the assumptions required for performing multivariate analysis of covariance (MANCOVA). Table 4 tabulates the descriptive indicators with the results of the covariance analysis.

As shown in Table 3, there is a significant difference between at least one of the variables of internal cohesion and controlling behaviors of couples faced with marital infidelity who were treated and couplecontrolled marital infidelity $(\mathrm{P}<0.05)$.

As shown in Table 4, there is a significant difference in the variables of internal cohesion and controlling behaviors of couples faced with marital infidelity of the experimental group, compared to that of the control group. As the results indicated, the levels of significance obtained for internal cohesion and controlling behaviors were lower, compared to the significance level of 0.001 obtained from the Bonferroni correction.

\section{Discussion}

According to the results of the present study, the means of the posttest stage indicated that the integrated EFT and Gottman's model had a significant effect on controlling behaviors and internal cohesion, compared to those reported for the control group. The results of the present study are in line with the findings of studies carried out by Wiebe et al. [31], Wiebe et al. [32], and Wiseman et al. [33]. In this regard, Fincham et al. [34] conducted a study on an integrated EFT and Gottman's model and its effectiveness in the quality of marital relations among married women. The results of the aforementioned study demonstrated that teaching integrated EFT and Gottman's model significantly increased the quality of the marital relationship and 
all its six subscales (i.e., satisfaction, trust, commitment, sexual passion, intimacy, and love). In addition, the effectiveness of the present integrated model training was lasting after a month. Therefore, the results showed that training the integrated EFT and Gottman's model was used to improve the quality of marital relations among married women. The results of the current study also demonstrated that EFT identifies negative emotions and individual's maladaptive emotions by emphasizing and targeting the behaviors in a stepwise fashion, respectively, and finally tries to change them with some methods and techniques [35]. In this treatment, individuals learn how to identify their range of emotions and that of others and how to adjust and manage them. Intense negative emotions are considered among the most common causes of harm to women through infidelity. In addition, these individuals can be altered through identification, expression, and substitution due to feelings of shame, embarrassment, and anger caused by infidelity [36]. Moreover, it was shown that their emotional responses are accepted through techniques, such as validation, and the blocked experiences can be expressed without judgment and reproach [37].

Furthermore, internal cohesion among couples is improved due to the effect of appropriate communication on a couple's relationship damaged by infidelity and core of the Gottman's approach as the right way to talk and listen to each other in marital relationships [35]. Obviously, communication problems and inability of couples affected by infidelity to properly and correctly communicate are among the most important causes of conflicts leading to dissatisfaction, incompatibility, and lower quality of marital life.

In addition, the couples' awareness of the right communication skills results in greater satisfaction and compatibility in marital life. Therefore, training couples through Gottman's approach prevents unhealthy communication patterns in couples and improves their relationships, which in turn increases the compatibility or prevents or reduces the incompatibility of couples, which has the preventive, developmental, and healing roles [37]. The limitations of the present study were the short duration of the training sessions in comparison to the depth of the psychological harm. In addition, it was not possible to control the intervening variables, such as limited age range and number of children, due to the difficulty of access to the desired subjects. It is recommended that family counselors and psychologists use the therapies presented in the current study, especially the integrated EFT and Gottman's model, to increase the compatibility and cohesion of couples' relationships.

\section{Conclusions}

It can be concluded that the combination of EFT and Gottman's therapy is an effective pattern in couples affected by infidelity and can be used as one of the therapeutic or educational methods in couple therapy programs.

\section{Compliance with ethical guidelines}

All the ethical principles were observed in the present study. The participants were informed about the purpose of the study and implementation of the stages. In addition, informed consent was obtained from all the study subjects. The participants were also assured of the confidentiality of their information. Moreover, the subjects were free to withdraw from the study at any time, and the results of the study would be available to them if desired.

\section{Acknowledgments}

The authors would like to express their gratitude to the participants who greatly cooperated with this research project.

\section{Authors' contributions}

Conceptualization [Mahdieh Hashemi]; Methodology [Javad Khalatbari]; Investigation [Javad Khalatbari]; Writing Original Draft [Shohreh Ghorban Shiroudi]; Writing, Review, and Editing [All authors]; Funding Acquisition [All authors]; Resources [All authors]; Supervision [Javad Khalatbari]

\section{Funding/Support}

The current study did not receive any specific grant from funding agencies in public, commercial, or not-for-profit sectors.

\section{Conflicts of Interest}

The authors declare that there is no conflict of interest.

\section{References}

1. Adamson NA. Emotionally focused therapy with couples facing breast cancer: a theoretical foundation and descriptive case study. Journal of Psychosocial Oncology. 2013; 31(6):712-26. [DOI:10.1080/07347332.2013.835024] [PMID]

2. Yu Y, Wu D, Wang JM, Wang YC. Dark personality, marital quality, and marital instability of Chinese couples: an actorpartner interdependence mediation model. Personality and Individual Differences. 2020; 154:109689. [DOI:10.1016/ i.paid.2019.109689]

3. Alavi M, Mei TK, Mehrinezhad SA. The dark triad of personality and infidelity intentions: the moderating role of relationship experience. Personality and Individual Differences. 2018; 128:49-54. [DOI:10.1016/j.paid.2018.02.023]

4. Armstrong D, Shakespeare-Finch J, Shochet I. Predicting post-traumatic growth and post-traumatic stress in firefighters. Australian Journal of Psychology. 2014; 66(1): 38-46. [DOI:10.1111/ajpy.12032]

5. Chen L, Ngoubene-Atioky AJ. Does number of children moderate the link between intimate partner violence and marital instability among Chinese female migrant workers? Sex Roles. 2019; 80(11-12):745-57. [DOI:10.1007/s11199019-1017-x]

6. Hwang W, Yoon J, Silverstein M, Brown MT. Husband-wife religious discordance, marital satisfaction, and risk of marital dissolution in two generations. Journal of Family Issues. 2019; 40(9):1201-23. [DOI:10.1177/0192513X19835871]

7. Lim SA, Lee J. Gender differences in the relationships 
between parental marital conflict, differentiation from the family of origin, and children's marital stability. The American Journal of Family Therapy. 2020; 48(5):1-6. [DOI:10.1080/01926187.2020.1747370]

8. Babcock JC, Gottman JM, Ryan KD, Gottman JS. A component analysis of a brief psycho-educational couples' workshop: one-year follow-up results. Journal of Family Therapy. 2013; 35(3):252-80. [DOl:10.1111/1467-6427.12017]

9. Balderrama-Durbin C, Stanton K, Snyder DK, Cigrang JA, Talcott GW, Smith Slep AM, et al The risk for marital infidelity across a year-long deployment. Journal of Family Psychology. 2017; 31(5):629-34. [DOI:10.1037/fam0000281] [PMID]

10. Barni D, Danioni F. Adolescents' basic personal values and sense of coherence. Personality and Individual Differences. 2016; 102:46-50. [DOI:10.1016/i.paid.2016.06.053]

11. Batabyal AA. Marital infidelity: a game-theoretic analysis. Journal of Quantitative Economics. 2018; 16(1):227-33. [DOI:10.1007/s40953-017-0081-8]

12. Berger R, Weiss T. The posttraumatic growth model: an expansion to the family system. Traumatology. 2009; 15(1):63-74. [DOI:10.1177/1534765608323499]

13. Bloch L, Haase CM, Levenson RW. Emotion regulation predicts marital satisfaction: More than a wives' tale. Emotion. 2014; 14(1):130-44. [DOI:10.1037/a0034272] [PMID] [PMCID]

14. Boeckxstaens P, Vaes B, De Sutter A, Aujoulat I, van Pottelbergh G, Matheï $C$, et al. A high sense of coherence as protection against adverse health outcomes in patients aged 80 years and older. The Annals of Family Medicine. 2016; 14(4):337-43. [DOI:10.1370/afm.1950] [PMID] [PMCID]

15. Bracha E, Hoffenbartal D. The existence of sense of coherence in teaching situations among student-teachers. Procedia-Social and Behavioral Sciences. 2015; 180:722-9. [DOI:10.1016/j.sbspro.2015.02.185]

16. Bravo IM, White Lumpkin P. The complex case of marital infidelity: an explanatory model of contributory processes to facilitate psychotherapy. The American Journal of Family Therapy. 2010; 38(5):421-32. [DOI:10.1080/01926187. 2010.522491]

17. Brewer G, Abell L. Machiavellianism and sexual behavior: motivations, deception and infidelity. Personality and Individual Differences. 2015; 74:186-91. [DOI:10.1016/ j.paid.2014.10.028]

18. Brewer G, Hunt D, James G, Abell L. Dark triad traits, infidelity and romantic revenge. Personality and Individual Differences. 2015; 83:122-7. [DOI:10.1016/j.paid.2015.04.007]

19. Burgess Moser M, Johnson SM, Dalgleish TL, Lafontaine MF, Wiebe SA, Tasca GA. Changes in relationship-specific attachment in emotionally focused couple therapy. Journal of Marital and Family Therapy. 2016; 42(2):231-45. [DOI:10.1111/jmft.12139] [PMID]

20. Burgess Moser M, Johnson SM, Dalgleish TL, Wiebe SA, Tasca GA. The impact of blamer-softening on romantic attachment in emotionally focused couples therapy. Journal of Marital and Family Therapy. 2018; 44(4):640-54. [DOI:10.1111/jmft.12284] [PMID]

21. Conradi HJ, Dingemanse $P$, Noordhof A, Finkenauer C, Kamphuis JH. Effectiveness of the 'Hold me Tight' relationship enhancement program in a self-referred and a clinician-referred sample: an emotionally focused couples therapy-based approach. Family Process. 2018; 57(3):61328. [DOI:10.1111/famp.12305] [PMID]

22. Hajihasani M, Sim T. Marital satisfaction among girls with early marriage in Iran: Emotional intelligence and religious orientation. International Journal of Adolescence and Youth. 2019; 24(3):297-306. [DOI:10.1080/02673843.2018. 1528167]
23. Crozier S, Robertson N, Dale M. The psychological impact of predictive genetic testing for Huntington's disease: a systematic review of the literature. Journal of Genetic Counseling. 2015; 24(1):29-39. [DOI:10.1007/s10897-0149755-y] [PMID]

24. Dabhilkar M, Bengtsson L. Invest or divest? On the relative improvement potential in outsourcing manufacturing. Production Planning and Control. 2008; 19(3):212-28. [DOI:10.1080/09537280701830144]

25. David P. Wedding the Gottman and Johnson approaches into an integrated model of couple therapy. The Family Journal. 2015; 23(4):336-45. [DOI:10.1177/1066480715601675]

26. Davis D, Shaver PR, Vernon ML. Physical, emotional, and behavioral reactions to breaking up: The roles of gender, age, emotional involvement, and attachment style. Personality and Social Psychology Bulletin. 2003; 29(7):871-84. [DOI:10.1177/0146167203029007006] [PMID]

27. DeWall CN, Anderson CA, Bushman BJ. The general aggression model: theoretical extensions to violence. Psychology of Violence. 2011; 1(3):245. [DOI:10.1037/ a0023842]

28. Elfassi Y, Braun-Lewensohn O, Krumer-Nevo M, Sagy S. Community sense of coherence among adolescents as related to their involvement in risk behaviors. Journal of Community Psychology. 2016; 44(1):22-37. [DOI:10.1002/ jcop.21739]

29. Li X, Zhou N, Fang X, Cao H. Marital conflict resolution and marital affection in chinese marriage: integrating variablecentered and person-centered approaches. Marriage \& Family Review. 2020; 56(4):369-89. [DOI:10.1080/014 94929.2020.1712575]

30. Ferguson S, Browne J, Taylor J, Davis D. Sense of coherence and women's birthing outcomes: a longitudinal survey. Midwifery. 2016; 34:158-65. [DOI:10.1016/j.midw.2015. 11.017]

31. Wiebe SA, Johnson SM. A review of the research in emotionally focused therapy for couples. Family Process. 2016; 55(3):390-407. [DOI:10.1111/famp.12229] [PMID]

32. Wiebe SA, Elliott C, Johnson SM, Burgess Moser M, Dalgleish TL, Lafontaine MF, et al. Attachment change in emotionally focused couple therapy and sexual satisfaction outcomes in a two-year follow-up study. Journal of Couple \& Relationship Therapy. 2019; 18(1):1-21. [DOI:10.1080/ 15332691.2018.1481799]

33. Weissman N, Batten SV, Rheem KD, Wiebe SA, Pasillas RM, Potts W, et al. The effectiveness of emotionally focused couples therapy with veterans with PTSD: a pilot study. Journal of Couple \& Relationship Therapy. 2018; 17(1):2541. [DOI:10.1080/15332691.2017.1285261]

34. Fincham FD, May RW. Infidelity in romantic relationships. Current Opinion in Psychology. 2017; 13:70-4. [DOI:10.1016/j.copsyc.2016.03.008] [PMID]

35. Umubyeyi B, Mtapuri O. Approaches to marital conflict resolution: a perspective of democratic Republic of Congo migrants living in Durban, South Africa. Journal of Family Issues. 2019; 40(8):1065-85. [DOI:10.1177/0192513X19 833092]

36. Garanzini S, Yee A, Gottman J, Gottman J, Cole C, Preciado $M$, et al. Results of Gottman method couples therapy with gay and lesbian couples. Journal of Marital and Family Therapy. 2017; 43(4):674-84. [DOI:10.1111/jmft.12276] [PMID]

37. Geulayov G, Drory Y, Novikov I, Dankner R. Sense of coherence and 22-year all-cause mortality in adult men. Journal of Psychosomatic Research. 2015; 78(4):377-83. [DOI:10.1016/j.jpsychores.2014.12.010] [PMID] 